\title{
An Optimized Pyrolysis Technology with Highly Energy Efficient Conversion of Waste Plastics into Clean Fuel While Substantially Reducing Carbon Emission
}

\author{
Gordon Yu, Chih-Young Hung, and Isaac Hung
}

\begin{abstract}
Incineration has been the only effective way of reducing plastic waste after recycling in the modern societies, yet a better solution for processing waste plastics and simultaneously producing renewable energy is presented and demonstrated in this paper. R-ONE ${ }^{\mathrm{TM}}$, an optimized Pyrolysis technology converting varieties of plastic waste into clean and low sulfur content fuel which meets the most stringent international standard, emits no toxic gases such as Dioxins and other secondary pollution. $\mathrm{R}-\mathrm{ONE} \mathrm{TM}^{\mathrm{TM}}$ recycles $100 \%$ of its own output of syngas $(5-10 \%)$ as the major energy source while converting around $80 \%$ of the mixed plastic waste into high grade fuel; and the other $10-15 \%$ into carbon black. In comparison with incinerators, carbon dioxide production by $\mathrm{R}^{-O N E}{ }^{\mathrm{TM}}$ is around 100X lower. Furthermore, its energy efficiency (from the energy balance calculation) is one of the highest in the world compared to any renewable energy technologies or any waste processing technologies. Both of these objectives are reached by $\mathrm{R}-\mathrm{ONE} \mathrm{TM}^{\mathrm{TM}}$.
\end{abstract}

Index Terms-Clean diesel, pyrolysis, renewable energy, R-ONE, waste processing.

\section{INTRODUCTION}

Due to many good characteristics, such as its relatively low cost, ease of manufacture, versatility, and imperviousness to water; plastics have been used in a massive and growing range of products and have already substituted many traditional materials in most of their former uses. However, with plastic production increasing, plastic waste generation is also on the rise which in turn is causing serious environmental problems.

Global plastics production is currently estimated to be 300 million metric tons each year and is growing at a rate of $4 \%$ annually [1]. The World Bank projects that 1.3 billion metric tons of municipal solid waste (MSW) is generated each year, a number that is expected to grow to 2.2 billion metric tons per year (MTPY) by 2025 . Around $10 \%$ of the total MSW produced, or 130 Million MTPY, is plastic [2]. Since plastic waste virtually does not degrade, it persists for hundreds years after they are dumped in the dumpsites. Thus, this accumulation of plastic products is serious threat to the prospect of the ecosystem in general and to the health of human society in particular.

Manuscript received June 23, 2017; revised February 23, 2018.

Gordon $\mathrm{Yu}$ is with Taiwan Hsinchu Green Industry Association, Taiwan (e-mail: gordony@etouchic.com).

Chih-Young Hung is with the National Chiao Tung University, Taiwan. (e-mail: cyhung@nctu.edu.tw).

Isaac Hung is with EVP R-ONE, Taiwan (e-mail: isaachung@evptechnology.com).
As the calorific value of the plastics is comparable to that of hydrocarbon fuel, production of fuel from plastic waste could provide a good opportunity to utilize the waste as a better alternative to dumpsites. For example, the Ocean Recovery Alliance has identified the plastics-to-fuel (PTF) technologies as one potential solution to reducing plastic marine litter and the landfilling of end-of-life plastics [3]. Currently, there are three technologies used to convert plastic waste into energy, namely they are combustion, gasification and pyrolysis. Table I below shows various technologies and the types of materials they can convert.

Pyrolysis is a thermochemical decomposition of organic material at elevated temperatures in the absence of oxygen Using pyrolysis technology to convert plastic waste into fuel has long been cited as one appealing technology for solving plastic waste problems (Malkow 2005 [4]; Sørum et al. [5]. Smith et al., 2001 [6]). Wong et al. 2015 [7] and Kunwar et al. 2016 [8] offered very good reviews on the various studies that offered specific schemes and procedures in carrying out the pyrolysis process.

The issue of using pyrolysis technology to achieve the goal of PTF, however, is not purely a technology matter [9], [10]. The efficiency, and thus the cost, of conducting a specific pyrolysis technology is another matter of concern. A recent study by Ye (2016) examined the developments of various pyrolysis companies and the challenges that they face [11]. Ye pointed out that while there have been many attempts to develop a successful pyrolysis technology for several decades in many countries; they were not able to find an operating industrial-scale plant that is converting non-recycled plastics (NRP) to synthetic oils. Existing companies are either still under development, have shut down due to low oil prices, or are using a more homogenous plastic feedstock from industrial wastes. Combined with the low cost of oil and technical and economic process challenges that companies are facing in this developing field, it is currently not feasible to use material recover facility (MRF) residues as pyrolysis feedstock. However, the residues can be mixed with other pyrolysis feedstock. Municipalities can make changes to their recycling systems so as to increase the amount of NRP directed to MRF and, therefore, the amount of feedstock suitable for pyrolysis plants. However, there is no point in increasing the NRP stream until there is an economically viable pyrolysis plant that will use this stream to produce synthetic oil.

In this paper, we present an optimized pyrolysis technology which converts varieties of plastic waste into clean and ultra-low sulfur content fuel that meets the most 
stringent international standards while emitting no toxic gases such as dioxins and other secondary pollution. This proprietary technology, R-ONE ${ }^{\mathrm{TM}}$ of EVP, is currently being adopted in several new plants that are under construction.

\begin{tabular}{|c|c|c|c|c|c|c|c|c|c|}
\hline Types of materials/Reactor & $\begin{array}{c}\text { Batch and } \\
\text { semi-batch } \\
\text { reactor }\end{array}$ & $\begin{array}{l}\text { Fluidized } \\
\text { bed reactor }\end{array}$ & $\begin{array}{c}\text { Conical spouted } \\
\text { bed reactor }\end{array}$ & $\begin{array}{l}\text { Fixed bed } \\
\text { reactor }\end{array}$ & $\begin{array}{c}\text { Two stages } \\
\text { pyrolysis } \\
\text { system }\end{array}$ & $\begin{array}{l}\text { Screw } \\
\text { kiln } \\
\text { reactor }\end{array}$ & $\begin{array}{c}\text { Microwave } \\
\text { assisted } \\
\text { pyrolysis }\end{array}$ & $\begin{array}{c}\text { Pyrolysis in super } \\
\text { critical water }\end{array}$ & $\begin{array}{l}\text { Fluid } \\
\text { catalytic } \\
\text { cracking }\end{array}$ \\
\hline \multicolumn{10}{|l|}{$\mathrm{PE}$} \\
\hline \multicolumn{10}{|l|}{ PP } \\
\hline \multicolumn{10}{|l|}{ PS } \\
\hline \multicolumn{10}{|l|}{ PET } \\
\hline \multicolumn{10}{|l|}{ PVC } \\
\hline \multirow{2}{*}{\multicolumn{10}{|c|}{\begin{tabular}{|l|} 
PBD \\
HDPE
\end{tabular}}} \\
\hline \multirow{2}{*}{\multicolumn{10}{|c|}{\begin{tabular}{|l|} 
HDPE \\
LDPE
\end{tabular}}} \\
\hline & & & & & & & & & \\
\hline \multicolumn{10}{|l|}{ Waste Tire } \\
\hline \multicolumn{10}{|l|}{\begin{tabular}{|l|} 
Residual Oil \\
\end{tabular}} \\
\hline \multirow{2}{*}{\multicolumn{10}{|c|}{\begin{tabular}{|l|} 
Cover film \\
Tooth paste packaging
\end{tabular}}} \\
\hline & & & & & & & & & \\
\hline \multicolumn{10}{|l|}{\begin{tabular}{|l|} 
Computer Packaging materials \\
\end{tabular}} \\
\hline \multicolumn{10}{|l|}{ Makarwal coal } \\
\hline \multicolumn{10}{|l|}{ HDPE blended with gas vacuum oil } \\
\hline \multicolumn{10}{|l|}{ PS-polybutadience dissolved in LCO } \\
\hline \multicolumn{10}{|l|}{\begin{tabular}{|l|} 
PS dissovlved in benzene \\
\end{tabular}} \\
\hline \multirow{2}{*}{\multicolumn{10}{|c|}{\begin{tabular}{|l|} 
PE dissolved in toluene \\
\end{tabular}}} \\
\hline LDPE dissolved in commercial VGC & & & & & & & & & \\
\hline \begin{tabular}{|l|} 
Cracking of HDPE in phenol \\
\end{tabular} & & & & & & & & & \\
\hline
\end{tabular}

\section{IOPERATIONAL DATA OF R-ONE ${ }^{\mathrm{TM}}$ PLANT}

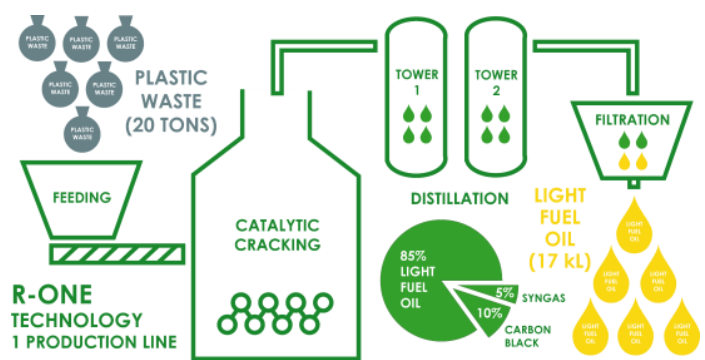

Fig. 1. Functional block diagram of R-ONE.

The functional diagram of R-ONE ${ }^{\mathrm{TM}}$ (Regenerated Oil \& New Energy), an optimized pyrolysis technology, is shown as Fig. 1, which is capable of processing 20 tons/day plastic waste. Below, the actual operational data from the demo plant using R-ONE ${ }^{\mathrm{TM}}$ technology is provided for discussion purposes: As illustrated in the mass balance flow chart of Fig. 2 , we use mixed plastic waste $[85 \%(\mathrm{PP}+\mathrm{PE}+\mathrm{PS})$ and $10 \%-15 \%$ others (ABS+PET+PVC...)] to evaluate the mass balance relations in $\mathrm{R}-\mathrm{ONE}^{\mathrm{TM}}$ process currently at EVP's demonstration facility in Hukou, the results show that the produced weights of fuel, syngas and carbon residue (carbon black) are 1,588.22 kg/day, $177.40 \mathrm{~kg} /$ day and $208.70 \mathrm{~kg} /$ day giving the produced ratio of fuel, syngas and carbon residue at $79.41 \%, 8.87 \%$ and $10.44 \%$ by weight.

In addition to thermal energy (lower than $400^{\circ} \mathrm{C}$ ) and proprietary-processing/molecular-recombination

technologies, R-ONE ${ }^{\mathrm{TM}}$ also utilizes 3 types of heterogeneous catalyst at 3 stages of the production process: pre-melt feeding, cracking, and filtration respectively. Every $1,000 \mathrm{~kg}$ of plastic waste processed requires $39.35 \mathrm{~kg}$ of catalysts which end up as carbon residues when the $\mathrm{R}-\mathrm{ONE}^{\mathrm{TM}}$ process is completed.

The R-ONE ${ }^{\mathrm{TM}}$ system uses three energy sources: electricity, optional diesel fuel, and syngas. Electricity is used only at the pre-melt feeding and stirring process, and requires $250 \mathrm{~kW}$ for 1 ton of plastic processed. R-ON ${ }^{\mathrm{TM}} \mathrm{E}$ diesel fuel (Calorific Value: 11,000 Kcal/Kg or 9,197 Kcal/L with density of $0.836 \mathrm{Kg} / \mathrm{L}$ ) is used only at the initial starting of the reactor, and requires 16.07 liters for 1 tons of plastic processed. The rest of the production process uses syngas generated by $\mathrm{R}-\mathrm{ONE} \mathrm{T}^{\mathrm{TM}}$ process, and it is entirely, internally sustained. Fig. 3 is the energy balance relation graph to illustrate.

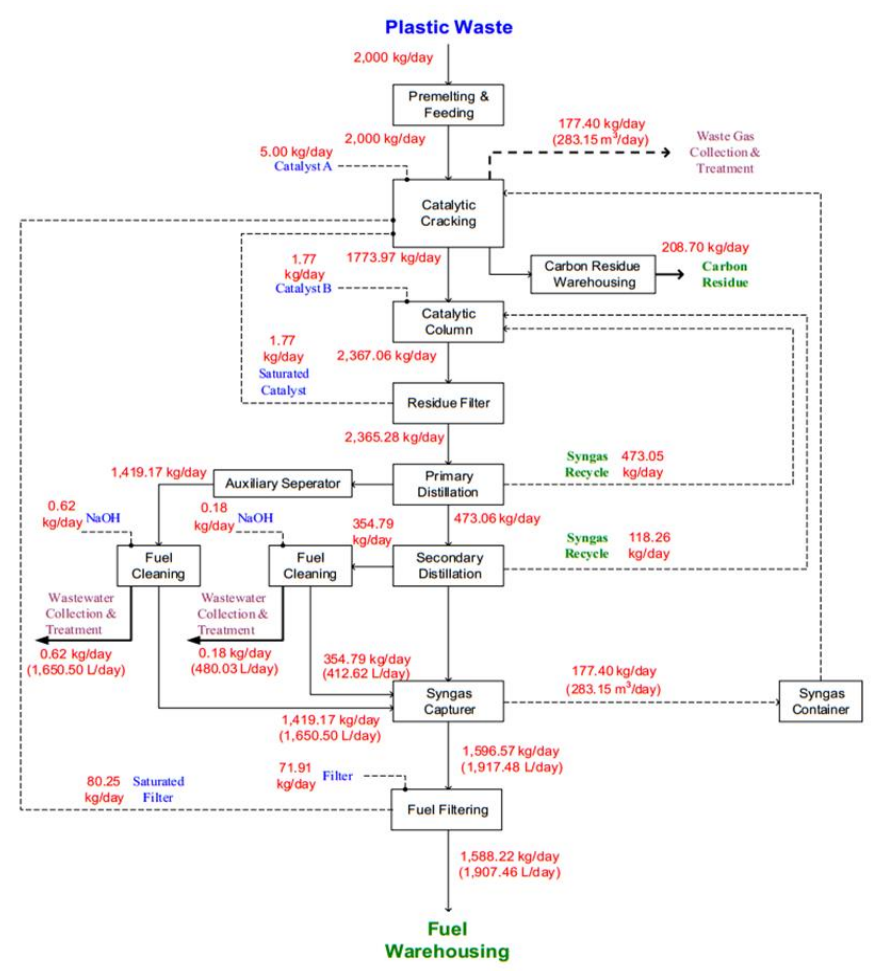

Fig. 2. R-ONE mass balance flow chart.

If such waste plastic of 2 tons/day were processed by incineration (which is the majority of the cases in Taiwan) then the carbon dioxide emission (Plastic: $75.1 \mathrm{Kg} \mathrm{CO}_{2} / \mathrm{GJ}$ ) will be:

$15,520,000 \mathrm{Kcal} /$ day $\times 4.1848 \mathrm{~J} / \mathrm{cal} \times 75.1 \mathrm{Kg} \mathrm{CO} / \mathrm{GJ}=$ $4,880 \mathrm{Kg} \mathrm{CO}_{2} /$ day

Since $\mathrm{R}-\mathrm{ONE} \mathrm{TM}^{\mathrm{TM}}$ is the thermal disintegration of 
carbonaceous material such as plastics in an oxygen-starved atmosphere and the larger hydrocarbon chains break down into smaller molecules; there is almost no carbon dioxide emission in the main process. However small amounts of carbon dioxide are generated due to the sustained fuel of syngas generated by $\mathrm{R}-\mathrm{ONE}^{\mathrm{TM}}$ or initial use of optional diesel fuel. When burning the syngas, the carbon dioxide emission (Sysngas: $56,100 \mathrm{Kg} \mathrm{CO}_{2} / \mathrm{TJ}$ ) will be:

\section{$295,617 \mathrm{Kcal} /$ day x $4.1848 \mathrm{~J} / \mathrm{cal}$ x 56,100 $\mathrm{Kg} \mathrm{CO}_{2} / \mathrm{TJ}=69$} $\mathrm{Kg} \mathrm{CO}_{2}$ /day

$\mathrm{R}-\mathrm{ONE}^{\mathrm{TM}}$ can reduce about $\sim 70 \mathrm{X} \mathrm{CO}_{2}$ emission for plastic waste treatment compared to incineration or so-called Waste To Energy (WTE). The component analysis report of Table II (2014/07/21 tested by SGS) [12] shows that R-ONE carbon residue contains $54.34 \mathrm{wt} \%$ ash, $33.24 \mathrm{wt} \%$ volatile matter and $12.42 \mathrm{wt} \%$ fixed carbon. Calorific value of the carbon residue becomes relatively low with $1,583 \mathrm{Kcal} / \mathrm{Kg}$ due to high contents of ash. From the viewpoint of energy transfer rate, the gross calorific value of raw waste plastics is about $7,760 \mathrm{Kcal} / \mathrm{kg}$. In other words, about $79.6 \%$ energy has been directly converted to R-ONE ${ }^{\mathrm{TM}}$ fuel product. Compared with most incinerators (or WTEs) where energy conversion efficiency are in the low 20's, typical pyrolysis is much better, while this test result confirms that R-ONE ${ }^{\mathrm{TM}}$ is the most efficient waste plastic processing and refinery process of all other renewable energy technologies.

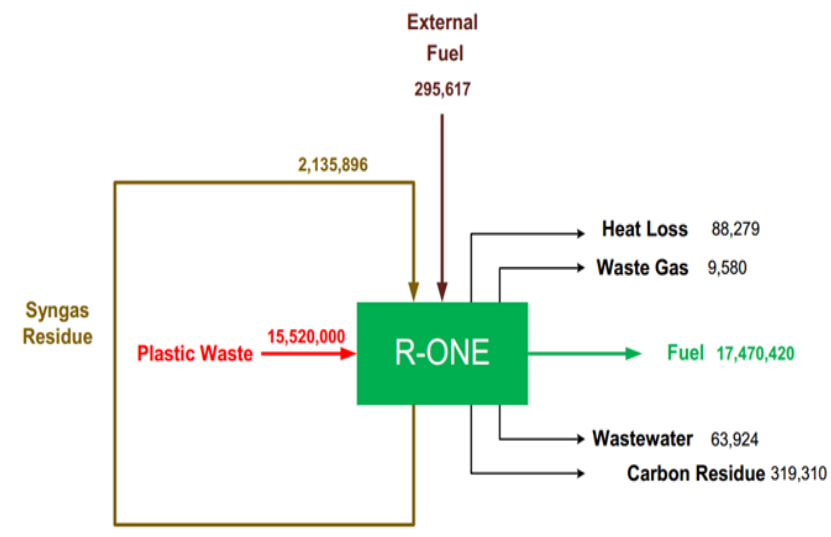

Fig. 3. Energy balance relation graph.

Unit: Kcal/day/module

TABLE II: SGS CERTIFIED TEST REPORT OF R-ONE CARBON REDIDUE

\begin{tabular}{lccc}
\multicolumn{1}{r}{ TEST ITEM(S) } & UNIT & METHOD & RESULT \\
ASH & wt $\%$ & ASTM D3174-12 & $\mathbf{5 4 . 3 4}$ \\
VOLATILE MATTER & wt $\%$ & ASTM D3175-11 & $\mathbf{3 3 . 2 4}$ \\
FIXED CARBON & wt $\%$ & ASTM D3172-13 & $\mathbf{1 2 . 4 2}$ \\
TOTAL SULFUR & wt $\%$ & ASTM D4239-13e1 & $<\mathbf{0 . 0 5}$
\end{tabular}

Heavy metals are found in $\mathrm{R}-\mathrm{ONE}^{\mathrm{TM}}$ carbon residue, such as Lead, Nickel, Zinc, Copper, Chromium, Antimony and Barium which are considered to have come from the feedstock of waste plastics. This is unavoidable as these heavy metals are the additives of plastic. Fortunately, they can be separated out during the purification process of carbon black. R-ONE ${ }^{\mathrm{TM}}$ carbon residue, with determined mean size of $20 \mu \mathrm{m}$, is easily filtered. Therefore, there will not be any air pollution problems during its collection, transportation, and treatment.

\section{RESUlTS AND DisCUSSION}

\section{A. Treatment Advantages}

R-ONE ${ }^{\mathrm{TM}}$ Technology features several advantages; it can process varieties of mixed plastic waste, as demonstrated by the above data which is obtained by processing $[85 \%$ $(\mathrm{PP}+\mathrm{PE}+\mathrm{PS})$ and $10 \%-15 \%$ others $(\mathrm{ABS}+\mathrm{PET}+\mathrm{PVC} \ldots)]$, in a manner of without cleaning and without sorting, so R-ONE ${ }^{\mathrm{TM}}$ eventually can reach the goal of processing NRP, especially for MRF residues, making it the best companion for recycling facilities. Also, its "High Temperature Residue Removal Technique" enables the removal of residues while maintaining the reactor's temperature at an ideal level. This technique not only keeps production running continuously, but also reduces energy consumption and ensures the safety of operators. In addition, $\mathrm{R}-\mathrm{ONE}^{\mathrm{TM}}$ production lines are assembled with a modular design concept, connecting ten individual reactors together. This allows maintenance to be done on each reactor individually without stopping production of the rest of the production line. Taking the scarcity of natural resources into consideration, R-ONE ${ }^{\mathrm{TM}}$ Technology is self-sustained in that the syngas generated is fully recycled as the production's heating source.

In contrast to conventional landfill and incineration, $\mathrm{R}-\mathrm{ONE}^{\mathrm{TM}}$ treatment is environmentally friendly while generating no pollutants to soil and underground water. Burning plastics typically will produce toxic material such as Dioxin, yet under the Oxygen-starvation condition and relative low temperature $\left(<400{ }^{\circ} \mathrm{C}\right)$, R-ONE ${ }^{\mathrm{TM}}$ does not generate Dioxin at all, SGS test report also confirms that. Also, R-ONE ${ }^{\mathrm{TM}}$ production yields very low emissions, in several orders of magnitude smaller than the regulation standard for controlled pollutants such as PM2.5, $\mathrm{SO}_{2} \&$ NOx (Table III).

TABLE III: SGS CERTIFIED EMISSION REPORT OF R-ONE PRODUCTION

\begin{tabular}{|c|c|c|c|c|c|c|}
\hline \multirow{2}{*}{$\begin{array}{c}\text { Air Pollutants and } \\
\text { Test Methods }\end{array}$} & $\mathbf{C 0 2}$ & $\mathbf{0 2}$ & Actual Value & Unit & Emission (kg/hr) & $\begin{array}{c}\text { Cmission Standard } \\
\text { (Taiwan) }\end{array}$ \\
\cline { 2 - 5 } & 4.7 & 14.5 & 13.3 & $\mathrm{mg} / \mathrm{Nm} 3$ & $8.91 \mathrm{E}-04$ & $500(\mathrm{mg} / \mathrm{Nm} 3)$ \\
\hline $\begin{array}{c}\text { Particulate matter (PM) } \\
\text { NIEA A101.74C }\end{array}$ & 5.5 & 16.25 & 18.6 & $\mathrm{ppm}$ & $3.35 \mathrm{E}-03$ & $650(\mathrm{ppm})$ \\
\hline $\begin{array}{c}\text { Sulfur dioxide (SO2) } \\
\text { NIEA A413.74C }\end{array}$ & 5.5 & 16.25 & 11.8 & $\mathrm{ppm}$ & $1.52 \mathrm{E}-03$ & $250(\mathrm{ppm})$ \\
\hline $\begin{array}{c}\text { Nitrogen oxides (NOx) } \\
\text { NIEA A411.74C }\end{array}$ & & & & & \\
\hline
\end{tabular}

\section{B. Production Outputs}

In $\mathrm{R}_{-O N E}{ }^{\mathrm{TM}}$ production (Fig. 3), the majority (80\%-85\%) of the plastic wastes are converted into light fuel oil. Compared to conventional fuel refinery methods, R-ONE follows a "Circular Economy" manner aiming to conserve natural resources. The World Economic Forum defines Circular Economy as following:

"A circular economy is an industrial system that is 
restorative or regenerative by intention and design. It replaces the end-of-life concept with restoration, shifts towards the use of renewable energy, eliminates the use of toxic chemicals, which impair reuse and return to the biosphere, and aims for the elimination of waste through the superior design of materials, products, systems and business models." [13]

In this regard, $\mathrm{R}-\mathrm{ONE} \mathrm{T}^{\mathrm{TM}}$ Technology takes waste as a source for fuel generation, and produces light fuel oil with competitive specifications (Table IV). Better combustion efficiency with Cetane Index of 61.2, much better than typical petro-chemical diesel Cetane Index of 40+ (Table V), $\mathrm{R}_{-} \mathrm{ONE}^{\mathrm{TM}}$ either provides $10 \sim 15 \%$ higher horsepower, or reduce oil consumption by $10 \sim 15 \%$ compared with fossil-fuel diesel, from the data of $11096 \mathrm{kcal} / \mathrm{kg}$ Heat of Combustion (Table VI). Diesel-engine vehicles or equipments using $\mathrm{R}-\mathrm{ONE}^{\mathrm{TM}}$ emit almost no black smoke at all due to high Cetane number (better combustion efficiency) and low Micro Carbon Residue which is around 1/4 of fossil-fuel counterpart.

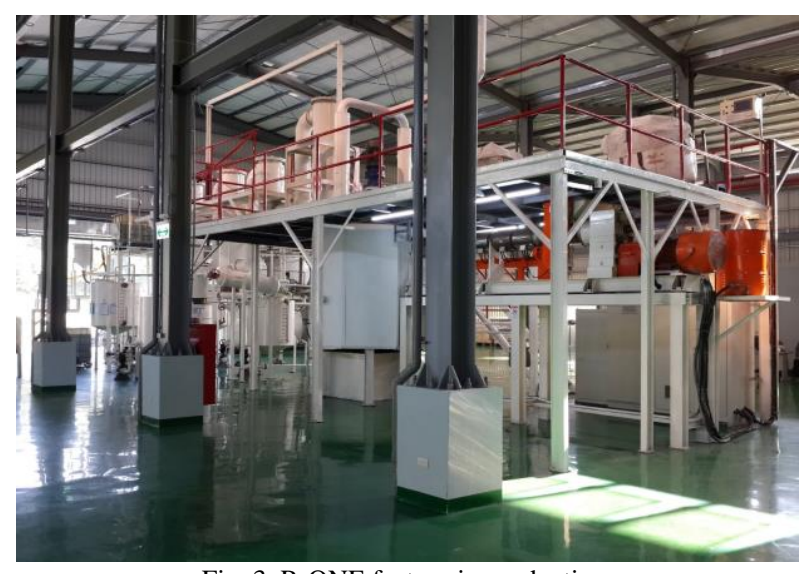

Fig. 3. R-ONE factory in production.

TABLE IV: SGS CERTIFIED TEST REPORT OF R-ONE LIGHT FUEL OIL

\begin{tabular}{|l|c|c|c|}
\hline TEST ITEM(S) & UNIT & METHOD & RESULT \\
\hline Flash Point & ${ }^{\circ} \mathrm{C}$ & ASTM D93 & 56.5 \\
\hline Heat of Combusiton & $\mathrm{kcal} / \mathrm{kg}$ & ASTM D240 & 11096 \\
\hline Cetane Index & --- & ASTM D4737 & 61.2 \\
\hline Sulfur(S) & $\mathrm{ppm}$ & ASTM D5453 & 10.7 \\
\hline Density, $15^{\circ} \mathrm{C}$ & $\mathrm{g} / \mathrm{mL}$ & ASTM D4052 & 0.8406 \\
\hline
\end{tabular}

While sulfur contributes heavily to acid rain formation [14] , R-ONE ${ }^{\mathrm{TM}}$ takes special consideration and generates renewable oil with only $10 \mathrm{ppm}$ of sulfur content, as a response to environmental awareness. MARPOL (The International Convention for the Prevention of Pollution from Ships) Annex VI entered into force for the Sulfur content no more than 35,000ppm for marine diesel started from 2012, which is also the current specification of CPC (China Petroleum Corp., the largest oil company in Taiwan) Fishing Boat Diesel Fuel B \& Fuel C [15]; the Sulfur content specification of cleanest CPC Fuel A is 10,000ppm, 1000 times higher than R-ONE's 10ppm. MARPOL's roadmap is to mandate Sulfur content from current $35,000 \mathrm{ppm}$ to 5000 ppm by 2020 (or 2025), the wide-spread of R-ONE ${ }^{\mathrm{TM}}$ will likely to make it happen earlier, or even push further to 1000ppm, the same with current mandate since 2015 in IMO (International Maritime Organization) designated Emission Control Areas (ECAs) such as East/West coasts of North America, North Sea \& Baltic Sea, etc. [16]

TABLE V: CHARACTERISTICS COMPARISON OF R-ONE

\begin{tabular}{|c|c|c|c|c|c|c|}
\hline \multirow{2}{*}{\multicolumn{2}{|c|}{ Unit }} & \multirow{2}{*}{\multicolumn{2}{|c|}{$\begin{array}{c}\text { R-ONE } \\
\text { Renewable Diesel }\end{array}$}} & \multicolumn{3}{|c|}{ Automotive Diesel } \\
\hline & & & & \multirow{2}{*}{\begin{tabular}{|c|} 
U.S.A \\
No.2 \\
40
\end{tabular}} & \multirow{2}{*}{$\begin{array}{c}\text { China } \\
\text { 0\# }\end{array}$} & \multirow{2}{*}{$\frac{\text { Taiwan }}{48}$} \\
\hline $\begin{array}{l}\text { Cetane } \\
\text { Number }\end{array}$ & & $\sim 60$ & $\begin{array}{c}\text { Better } \\
\text { Combustion }\end{array}$ & & & \\
\hline Sulfur & ppm & 10 & Clean & 15 & 50 & 10 \\
\hline $\begin{array}{c}\text { Oxidation } \\
\text { Stability }\end{array}$ & $\mathrm{g} / \mathrm{m} 3$ & 2.6 & Stable & - & 25 & 25 \\
\hline $\begin{array}{l}\text { Micro } \\
\text { Carbon } \\
\text { Residue }\end{array}$ & $\%$ & 0.08 & $\begin{array}{c}\text { Lower } \\
\text { Maintenance } \\
\text { Cost }\end{array}$ & 0.35 & 0.3 & 0.3 \\
\hline
\end{tabular}

TABLE VI: HEAT VALUE COMPARISON OF R-ONE

\begin{tabular}{|c|c|c|c|c|}
\hline Net Heat & R-ONE & \multicolumn{3}{|c|}{ Automobile Diesel } \\
\cline { 3 - 5 } Value & (PTO A Fuel) & U.S No.2 & China \#0 & Taiwan \\
\hline $\mathrm{kcal} / \mathrm{kg}$ & 11,096 & 10,125 & 9,181 & 9,600 \\
\hline
\end{tabular}

\section{CONCLUSION}

R-ONE ${ }^{\mathrm{TM}}$ Technology converts plastic waste into light fuel oil without generating toxic byproduct such as Dioxin, with little or no emissions, which can potentially reduce environmental burdens. The treatment follows a sustainable spirit in order to conserve natural resources and mitigate global warming; the carbon dioxide emission is reduced for almost $100 \mathrm{X}$ in compared with incinerator, and the energy conversion of close to $80 \%$ is among the highest in the world which makes R-ONE ${ }^{\mathrm{TM}}$ potentially be the most efficient renewable energy apparatus. The output contains competitive specifications in terms of environmental protection such as $1,000 X$ lower in Sulfur content, and economical optimization of $10 \sim 15 \%$ more horsepower or less oil consumption. In response to the currently overloading plastic wastes in Hong Kong resulting from China's "Green Fence" policy, R-ONE ${ }^{\mathrm{TM}}$ stands as a viable solution ought to be considered; R-ONE ${ }^{\mathrm{TM}}$ will be needed whenever there are tons of plastic waste, which virtually are every nation and every city, whether it's on the land, or by the sea and even under the sea.

\section{ACKNOWLEDGEMENT}

Special gratitude to EVP R-ONE ${ }^{\mathrm{TM}}$ Market Development team, eTouch Innovation Co. Ltd. and National Chiao Tung University New Energy Research Lab.

\section{REFERENCES}

[1] Plastics Europe. Plastics - The facts 2013. [Online]. Available: http://www.plasticseurope.org/documents/document/2013101409582 4final_plastics_the_facts_2013_published_october2013.pdf

[2] The World Bank, "What a waste: A global review of solid waste management," March 2012.

[3] 2015 Plastics-to-Fuel Project Developer's Guide, Prepared By: Ocean Recovery Alliance, June 2015.

[4] M. Thomas, "Novel and innovative pyrolysis and gasification technologies for energy efficient and environmentally sound MSW disposal," Waste Management, vol. 24, 2004, pp. 53-79.

[5] L. Sørum et al., "Pyrolysis charactersitcics and kinetcics of municipal solid wastes," Fuel, vol. 80, pp. 1217-1227, 2001.

[6] A. Smith et al., "Waste management options and climate change: Final report," Rep. Prepared by AEA Technology for the European Commission, DG Environment; B4-3040/99/136556/MAR/E3, 2001. 
[7] S. L. Wong et al., "Current state and future prospects of plastic waste as source of fuel: A review," Renewable and Sustainable Energy Reviews, vol. 50, pp. 1167-1180, 2015.

[8] K. Bidhya et al., "Plastics to fuel: A review," Renewable and Sustainable Energy Reviews, vol. 54, 2016, pp. 421-428.

[9] L. Y. Lin et al., "Preferential policies promote municipal solid waste (MSW) to energy in China: Current status and prospects," Renewable and Sustainable Energy Reviews, vol. 36, 2014, pp. 135-148.

[10] H. Zhou et al., "An overview of characteristics of municipal solid waste fuel in China: Physical chemical composition and heating value, Renewable and Sustainable Energy Reviews, vol. 36, 2014, pp. $107-122$

[11] Y. Diane, "Developments in industrial scale pyrolysis of non-recycled plastics (NRP)," Columbia University, 201.

[12] SGS Taiwan Ltd. Test Report \#KI/2014/70289, Product: "R-ONE Carbon Black", July 28, 2014.

[13] World Economic Forum, "Towards the circular economy: Accelerating the scale-up across global supply chains," Geneva, Switzerland, January 2014.

[14] United States Environmental Protection Agency. (2014). Causes of acid rain. [Online]. Available: http://www.epa.gov/region1/eco/acidrain/causes.html

[15] Specification of Petroleum, CPC Corp, Taiwan, Version 7.9, April 2012.

[16] Edmund Hughes, "MARPOL annex VI - An update of international regulatory developments for prevention of air pollution and the energy efficiency of ships," July 2016 Global Shippers' Forum AGM Colombo, Sri Lanka.

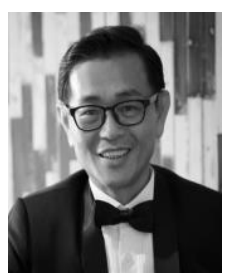

Gordon Yu got the MSEE 1987 University of Texas, Arlington, Texas USA, the BSEE 1979 National Chiao Tung University, Hsinchu, Taiwan.

$\mathrm{He}$ is currently the CEO of Etouch Innovation Co. Ltd., managing director \& chief strategy officer of EVP, chief strategy officer of UWin Nanotech, and managing director of Taiwan Hsinchu Green Industry Association, all based in Taiwan. More than 150 patents holder in Taiwan, China, USA and EU, he has been awarded Taiwan $9^{\text {th }}$ "Innovative research Award" by Minister of Economic Affairs, $5^{\text {th }}$ "Rising Star Award" by the Prime Minister, and 11 $1^{\text {th }}$ "National Award of Outstanding SME" by the President of Taiwan.
Mr. Yu has been a frequent invited Speaker for Sustainability around the world such as "International Conference on Solid Waste, Hong Kong, May 2015, "ECO Technology Show" Brighton, UK, June 2015, "Global Bioeconomy Summit", Berlin, Germany, Nov. 2015, "International Conference on Synergy between Science and Social Development in Solid Waste Management", Hong Kong, Sept,. 2016, and "EU-Taiwan Green Summit: Moving towards a Circular Economy and Sustainable Trade", Taipei, Nov. 2016, etc. Mr. Yu is a member of Taiwan Cradle-to-Cradle Alliance and a Board member of Taiwan Hsinchu Green Industry Association.

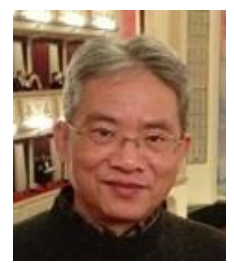

Chih-Young Hung earned his B.S in electrical engineering from National Chiao Tung University, Hsinchu, Taiwan in 1979, MA in management from Sonoma State University, Rohnert Park, CA, USA, in 1984, and Ph.D. in finance from Texas Tech University, Lubbock, Texas USA in 1990.

He worked for ERSO/ITRI as an assistant R\&D engineer for two years. His main task involved the design and implementation of circuit board for an industrial robot's controller. He joined and remains at his current job as a professor at the National Chiao Tung University since 1990 . He has published several books and also papers in various academic journals. His main research interests are in the area of technology foresight, assessment and selection.

Professor Chih-Young Hung is the Honorary Chairman of the Chinese Valuation Association, Taiwan. He is a board member of the Chinese Society of the Management of Technology.

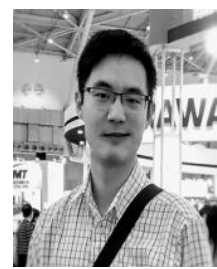

Isaac Hung got the MSBE 2016 in water resource engineering University of Arizona, Tucson, Arizona USA, the BSBE 2014 in controlled environment agriculture University of Arizona, Tucson, Arizona USA.

$\mathrm{He}$ is currently an assistant project manager at EVP R-ONE in Taipei City, Taiwan. Mr. Hung has worked with ultrafine bubbles at GAIA USA, Inc and engineering projects at Bosque Engineering, LLC.

Mr. Hung is a member of the American Water Works Association and the American Society of Agricultural and Biological Engineers. 